\title{
Beyond taxanes: the next generation of microtubule-targeting agents
}

\author{
Javier Cortes $\cdot$ Maria Vidal
}

Received: 17 October 2011/Accepted: 3 November 2011/Published online: 24 November 2011

(C) The Author(s) 2011. This article is published with open access at Springerlink.com

\begin{abstract}
Taxanes are a standard first-line option for metastatic breast cancer (MBC), but their utility may be limited by primary or acquired resistance. New microtubule-targeting agents have been developed to overcome taxane resistance and provide additional options for improving patient outcomes. This article reviews these alternative microtubule-targeting agents and their potential clinical benefits for MBC patients. Relevant clinical data were compiled through searches within PubMed and congress abstract databases. Ixabepilone, a novel microtubulestabilizing drug approved by the US Food and Drug Administration (FDA), has proven efficacy across multiple lines of therapy, including patients with taxane-resistant/ refractory disease. In phase III trials, ixabepilone plus capecitabine significantly improved progression-free survival compared with capecitabine alone in anthracycline/ taxane-pretreated patients. Eribulin has recently been approved by the FDA and by the European Medicines Agency for the treatment of patients with $\mathrm{MBC}$ who have received at least two prior chemotherapy regimens for latestage disease. In a phase III trial, eribulin extended overall survival compared with the physician's treatment choice in heavily pretreated MBC patients. In addition, several investigational microtubule-targeting agents may have therapeutic potential in MBC. The development of new microtubule-targeting agents helps to address the need for additional effective regimens for patients progressing after standard treatment with anthracycline- and taxane-containing regimens.
\end{abstract}

J. Cortes $(\square) \cdot$ M. Vidal

Breast Cancer Program, Department of Oncology, Vall d'Hebron University Hospital, Vall d'Hebron 119-129, Barcelona, Spain

e-mail: jacortes@vhio.net
Keywords Taxanes - Microtubule-targeting agents · Epothilones · Ixabepilone · Eribulin

\section{Introduction}

Recurrent or metastatic breast cancer (MBC) continues to be an incurable disease with a poor prognosis and a median 5-year survival of only 23-26\% [1, 2]. Effective long-term management of MBC poses significant clinical challenges. Modern chemotherapeutic approaches aim to improve survival duration and palliate symptoms while minimizing toxicity and maintaining quality of life [3]. Taxanes, such as paclitaxel and docetaxel, are a cornerstone of treatment across multiple lines of therapy. However, the clinical usefulness of these microtubule inhibitors is often constrained by primary or acquired resistance, the latter frequently resulting from taxane use in the adjuvant or neoadjuvant setting $[4,5]$. Resistance underscores the need for additional treatment options for women progressing on standard chemotherapy. Reviewed in this article are several novel antineoplastic drugs targeting microtubules that have provided new treatment options for patients with MBC resistant to taxane therapy. Relevant clinical data were compiled through searches within PubMed and congress abstract databases with no date limits, specific inclusion, or exclusion criteria applied.

\section{Treatment approach and role of taxanes in $\mathrm{MBC}$}

The selection of treatment for $\mathrm{MBC}$ is strongly influenced by the estrogen receptor (ER), progesterone receptor (PR), and human epidermal growth factor receptor 2 (HER2) status of the tumor $[3,6]$. Systemic chemotherapy is 
appropriate for women whose disease is refractory to endocrine therapy, hormone receptor-negative, or rapidly progressive with visceral involvement [3, 6]. In this setting, combination chemotherapy is associated with a rapid response but greater toxicity and similar survival outcomes compared with the sequential use of single cytotoxic drugs $[3,6]$. For women with HER2-positive disease, trastuzumab-based therapy is the standard of care, and lapatinib plus capecitabine is a reasonable option in trastuzumabrefractory disease $[3,6]$. The antiangiogenic drug bevacizumab improved progression-free survival (PFS) when added to weekly paclitaxel, 3-weekly docetaxel, and capecitabine in first-line treatment of MBC [7-9]. Overall survival (OS) was not prolonged compared with chemotherapy alone but OS is difficult to observe in setting with a long post-progression survival such as first-line HER2negative MBC [10].

\section{Taxane resistance}

The increased use of taxanes in early-stage breast cancer has lead to higher rates of resistance to these drugs by the time of disease recurrence, thereby reducing their effectiveness and usefulness in the treatment of MBC. Even among taxane-naïve patients, primary resistance to taxanes is a critical factor for disease progression. Taxane resistance rates of up to $55 \%$ have been reported in anthracycline-pretreated patients and up to one-third of anthracycline-naïve patients [4].

Taxanes bind reversibly to $\beta$-tubulin, which stabilizes microtubule complexes and promotes microtubule polymerization leading to cell-cycle arrest and apoptosis [11]. Resistance to taxanes can develop via a number of different mechanisms. The overexpression of P-glycoprotein and other ATP-binding cassette transport proteins promotes drug efflux from the tumor cell, which effectively reduces drug concentrations at target sites. P-glycoprotein, encoded by the $M D R-1$ gene, confers resistance to both taxanes and anthracyclines [12]. Taxane resistance can also develop from $\beta$-tubulin gene mutations, overexpression of $\beta$ IIItubulin or microtubule-associated proteins, and alterations in mitotic checkpoint signaling proteins [13].

The $\beta$ III-tubulin isotype has a different amino acid sequence and post-translational modifications compared with other $\beta$-tubulin isotypes, which leads to reduced paclitaxel binding [14-16]. The overexpression of $\beta$ III-tubulin has been associated with clinical resistance to taxanes in several studies. For example, high versus low $\beta$ III-tubulin expression was predictive of progression on paclitaxelbased chemotherapy in a cohort of 70 patients with advanced breast cancer [17]. Similarly, $\beta$ III-tubulin overexpression was associated with a significantly higher rate of disease progression in a cohort of 92 advanced breast cancer patients receiving first-line paclitaxel-based chemotherapy (35 vs. $7 \%, P<0.002$ ) [18]. The development of new taxanes and new taxane formulations has not resolved the problem of primary and acquired resistance, which has driven the search for alternative agents that could be used in taxane-resistant disease or replace taxanes in early stages of treatment. A number of novel agents targeting microtubules have been recently developed for use in breast cancer.

\section{Epothilones: novel microtubule-targeting agents for $\mathrm{MBC}$}

The epothilones-identified initially from the myxobacterium Sorangium cellulosum [19]—are a novel class of microtubule-stabilizing drugs [20] that have low susceptibility to common mechanisms conferring resistance to taxanes and other cytotoxic agents, including P-glycoprotein overexpression [21]. Moreover, unlike the taxanes, the epothilones bind effectively to $\beta$ III-tubulin [16] and consequently retain activity in taxane-resistant tumors overexpressing $\beta$ III-tubulin [22, 23]. Ixabepilone is the only epothilone approved by the US Food and Drug Administration (FDA). Preclinical studies showed that ixabepilone, a semi-synthetic derivative of natural epothilone $B$, is active in taxane-sensitive and -resistant tumor cell lines and tumor xenografts [23, 24]. Preclinical studies also showed synergistic antitumor activity between ixabepilone and other anticancer drugs, including capecitabine [25, 26].

\section{Clinical activity of ixabepilone in MBC}

Ixabepilone is approved for use in locally advanced or $\mathrm{MBC}$, either as monotherapy following progression on an anthracycline, a taxane, and capecitabine, or in combination with capecitabine following failure of an anthracycline and a taxane. It may be used in early therapy lines of MBC resistant to these other drugs. Ixabepilone $\left(40 \mathrm{mg} / \mathrm{m}^{2}\right.$ once every 3 weeks), either alone or in combination with capecitabine $2,000 \mathrm{mg} / \mathrm{m}^{2} /$ day on days $1-14$, was effective with acceptable toxicity in clinical trials in MBC patients including those resistant to taxanes or heavily pretreated (Table 1) [27-31]. In phase II trials, objective response rates to ixabepilone monotherapy ranged from $11.5 \%$ in patients with $\mathrm{MBC}$ resistant to anthracyclines, taxanes, and capecitabine [27] to $57 \%$ in MBC patients previously untreated with taxanes [36]. Median survival of patients with taxane-resistant or anthracycline-, taxane-, and capecitabine-resistant disease treated with ixabepilone was 7.9 and 8.6 months, respectively [27, 28].

Combination therapy with ixabepilone plus capecitabine was superior to capecitabine alone after failure of anthracycline and taxane treatment in two large, randomized 


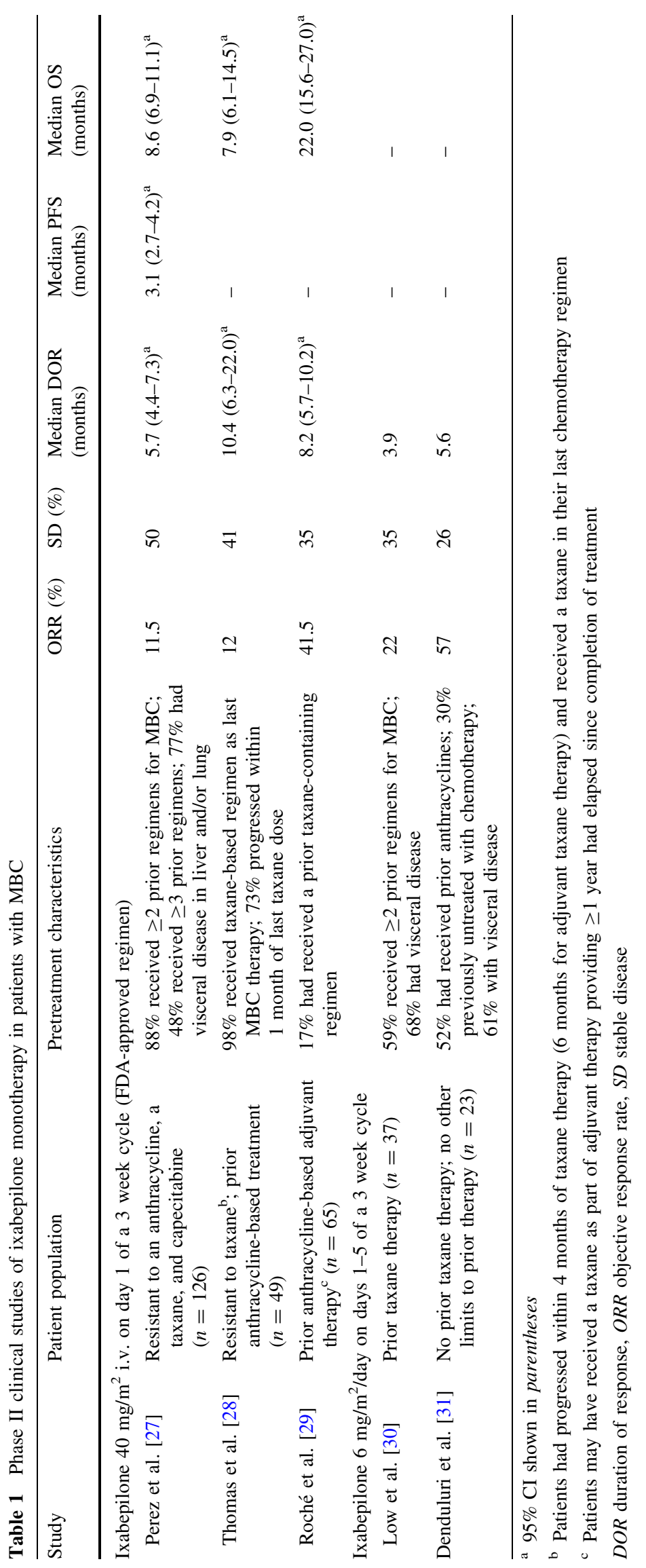


Table 2 Efficacy of ixabepilone in combination with capecitabine in patients with MBC in phase III trials

\begin{tabular}{|c|c|c|c|c|}
\hline & 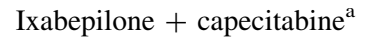 & Capecitabine monotherapy ${ }^{\mathrm{b}}$ & HR $(95 \% \mathrm{CI})$ & $P$ value \\
\hline \multicolumn{5}{|c|}{ Trial 046 (Yardley et al. [4]; Thomas et al. [32]; Hortobagyi et al. [33]) } \\
\hline Overall population $^{\mathrm{c}}$ & $n=375$ & $n=377$ & & \\
\hline $\mathrm{ORR}^{\mathrm{d}}, \%(95 \% \mathrm{CI})$ & $34.7(30-40)$ & $14.3(10.9-18.3)$ & - & $<0.0001$ \\
\hline Median PFS ${ }^{\mathrm{d}}$, months $(95 \% \mathrm{CI})$ & $5.8(5.5-7.0)$ & $4.2(3.8-4.5)$ & $0.75(0.64-0.88)$ & 0.0003 \\
\hline Median OS, months $(95 \% \mathrm{CI})$ & $12.9(11.5-14.2)$ & $11.1(10.0-12.5)$ & $0.90(0.77-1.05)$ & 0.1936 \\
\hline Subset with primary taxane resistance $\mathrm{e}^{\mathrm{e}}$ & $N=150$ & $N=137$ & & \\
\hline ORR, \% $(95 \% \mathrm{CI})$ & $33(25.9-41.5)$ & $13(8.0-20.0)$ & - & $<0.0001$ \\
\hline Median PFS, months (95\% CI) & $5.6(4.3-7.0)$ & $4.9(4.0-5.7)$ & 0.83 & - \\
\hline \multicolumn{5}{|c|}{ Trial 048 (Hortobagyi et al. [33], Sparano et al. [34]) } \\
\hline Overall population $^{\mathrm{f}}$ & $n=609$ & $n=612$ & & \\
\hline ORR, \% (95\% CI $)$ & $43.3(38.7-47.9)$ & $28.8(24.7-33.2)$ & - & $<0.0001$ \\
\hline Median PFS, months $(95 \% \mathrm{CI})$ & $6.2(5.6-6.8)$ & $4.4(4.1-5.4)$ & $0.79(0.69-0.90)$ & 0.0005 \\
\hline Median OS, months & $16.4(14.9-17.9)$ & $15.6(13.9-17.0)$ & $0.90(0.78-1.03)$ & 0.1162 \\
\hline \multicolumn{5}{|c|}{ a Ixabepilone $40 \mathrm{mg} / \mathrm{m}^{2}$ i.v. on day 1 plus oral capecitabine $1,000 \mathrm{mg} / \mathrm{m}^{2}$ twice daily on days $1-14$ of a 3 week cycle } \\
\hline \multicolumn{5}{|c|}{$\begin{array}{l}\text { c Patients with locally advanced or MBC previously treated with or resistant to anthracyclines and resistant to taxanes. Resistance was defined by } \\
\text { tumor progression during treatment or within } 3 \text { months of the last dose for MBC, or recurrence within } 6 \text { months of treatment in the adjuvant or } \\
\text { neoadjuvant settings }\end{array}$} \\
\hline \multicolumn{5}{|c|}{ d As determined by independent radiology review } \\
\hline \multicolumn{5}{|c|}{${ }^{\mathrm{e}}$ Primary resistance defined by progressive disease as best response in previous therapy } \\
\hline \multicolumn{5}{|c|}{${ }^{f}$ Patients with locally advanced or MBC treated previously with an anthracycline and a taxane } \\
\hline$O R R$ & & & & \\
\hline
\end{tabular}

phase III studies (Table 2) [4, 32-34]. The pivotal trial included 752 patients with advanced or MBC previously treated or resistant to anthracyclines and resistant to taxanes [32]. Ixabepilone plus capecitabine significantly prolonged median PFS relative to capecitabine monotherapy (5.8 vs. 4.2 months; $P=0.0003$ ) and reduced risk of disease progression by $25 \%$ [32]. Objective responses were more common with the combination than with capecitabine alone in overall population (35 vs. $14 \% ; P<0.0001)$ [32] and in patients with primary taxane resistance (33 vs. $13 \%$; $P<0.0001$ ) [4]. Median OS was not significantly longer in the combination therapy group (12.9 vs. 11.1 months; $P=0.19)$ [33].

Ixabepilone plus capecitabine was also evaluated in a larger phase III trial that enrolled 1,221 MBC patients previously treated with, but not necessarily resistant to, anthracyclines and taxanes [34]. Overall, 74\% of the study cohort was not resistant to anthracyclines and $52 \%$ were not resistant to taxanes. The combination regimen significantly improved median PFS (6.2 vs. 4.2 months; $P=0.0005$ ) and response rate (43 vs. $29 \% ; P<0.0001$ ) compared with single-agent capecitabine [34]. Despite the PFS benefit, a significant improvement in OS was not observed (16.4 vs. 15.6 months; $P=0.116$ ). Pooled analyses of the phase III clinical trials demonstrated that ixabepilone offers clinical benefits across a broad range of patients with advanced or MBC and within specific patient subsets, including taxaneresistant disease, relapse within 1 year of anthracycline/ taxane therapy, triple-negative breast cancer, symptomatic with a poor prognosis, and heavy visceral disease burdens to the liver and lung [4, 35-39].

The most common ixabepilone-related adverse event was peripheral neuropathy, which was primarily sensory and generally reversible with dose reduction or delay. In the two phase III trials, the incidence of peripheral neuropathy in the ixabepilone plus capecitabine arms was 67 and $66 \%$, respectively (including $22-24 \%$ grade 3 and $<1 \%$ grade 4) [32, 34].

Other ixabepilone-based combinations

Ixabepilone has also been evaluated in combination with other agents. In the phase II Eastern Cooperative Oncology Group E2103 trial, ixabepilone was administered at a dose of $15 \mathrm{mg} / \mathrm{m}^{2}$ in combination with trastuzumab and carboplatin area under curve 2 on days 1,8 , and 15 of a 4 week cycle to 59 patients with HER2-positive MBC as first-line therapy [40]. Trastuzumab was administered weekly (4 mg/ $\mathrm{kg}$ initially, then $2 \mathrm{mg} / \mathrm{kg}$ ) during chemotherapy, and then every 3 weeks $(6 \mathrm{mg} / \mathrm{kg})$ until disease progression. 
Objective responses were achieved in 26 patients (44\%); the median time to progression was 8.2 months and median OS was 34.7 months. The regimen had an acceptable tolerability profile and efficacy was assessed by investigators as comparable with that achieved with paclitaxel, carboplatin, and trastuzumab.

The feasibility of administering ixabepilone with an anthracycline was shown in two phase I trials. Ixabepilone plus pegylated liposomal doxorubicin (PLD) yielded objective responses in three of 13 patients (23\%) with taxane-pretreated advanced breast cancer [41]. The recommended regimen for further evaluation was ixabepilone $16 \mathrm{mg} / \mathrm{m}^{2}$ on days 1,8 , and 15 plus PLD $30 \mathrm{mg} / \mathrm{m}^{2}$ on day 1 of a 4 week cycle. Preliminary data from a phase Ib trial indicated that ixabepilone plus epirubicin has favorable efficacy in patients with advanced breast cancer who had a progression-free interval of $\geq 3$ months following adjuvant anthracyclines [42]. Partial responses were seen in 10 of 12 women with measurable disease. The suggested dose for further evaluation was ixabepilone $30 \mathrm{mg} / \mathrm{m}^{2}$ plus epirubicin $75 \mathrm{mg} / \mathrm{m}^{2}$ every 3 weeks.

Finally, ixabepilone plus bevacizumab was compared with paclitaxel plus bevacizumab as first-line therapy for HER2-negative MBC in a randomized phase II trial [43]. A total of 123 women were allocated to one of three treatment arms: ixabepilone $16 \mathrm{mg} / \mathrm{m}^{2}$ on days 1,8 , and 15 every 4 weeks plus bevacizumab $10 \mathrm{mg} / \mathrm{kg}$ every 2 weeks; ixabepilone $40 \mathrm{mg} / \mathrm{m}^{2}$ and bevacizumab $15 \mathrm{mg} / \mathrm{kg}$ every 3 weeks; or paclitaxel $90 \mathrm{mg} / \mathrm{m}^{2}$ plus bevacizumab according to the schedule in the first arm. The three-week regimen of ixabepilone/bevacizumab had similar efficacy to the paclitaxel/bevacizumab regimen; the weekly ixabepilone regimen was somewhat less effective but better tolerated.

\section{Other epothilones}

Other epothilones are currently in clinical development, including epothilone B (patupilone) and the epothilone B derivative sagopilone. To date, only limited data are available with these agents in breast cancer although activity has been shown across a range of solid tumor types including taxane-resistant tumors [44]. Patupilone (10 mg/ $\mathrm{m}^{2}$ every 3 weeks) is being evaluated in a phase II trial in MBC patients with brain metastases that progressed or recurred after whole brain radiation therapy; preliminary results indicated a partial response in one of the first 17 patients $(6 \%)$ [45]. Three-month PFS in the central nervous system was $8 \%$, and grade $3 / 4$ toxicities were mostly gastrointestinal events. The tolerability profile of patupilone may differ from that of ixabepilone, presumably because of differences in tissue distribution and metabolism [44].
Sagopilone is being investigated in a broad clinical program that includes breast cancer. In a phase II trial of 65 women with $\mathrm{MBC}$ who had previously received an anthracycline and a taxane, sagopilone 16 or $22 \mathrm{mg} / \mathrm{m}^{2}$ every 3 weeks produced three confirmed responses $(5 \%)$ [46]; sensory neuropathy and fatigue were the main treatment-related adverse events, occurring in 82 and $45 \%$ of patients, respectively. The investigators of this study concluded that sagopilone has limited activity in heavily pretreated MBC patients.

\section{Other novel microtubule-targeting agents}

Eribulin was recently approved by the FDA and the European Medicines Agency (EMA) for the treatment of patients with $\mathrm{MBC}$ who have received at least two prior chemotherapy regimens for late-stage disease. Several other novel non-taxane, non-epothilone, microtubule-targeting drugs are under early stages of clinical development.

\section{Eribulin}

Eribulin, a synthetic analog of the marine macrolide halichondrin $\mathrm{B}$, is a microtubule inhibitor with a unique mechanism of action. Eribulin inhibits microtubule stability by blocking microtubule growth without affecting microtubule shortening, thereby sequestering $\beta$-tubulin into nonfunctional aggregates and leading to formation of abnormal mitotic spindles and ultimately apoptosis [47, 48]. Phases I and II studies indicated that eribulin has activity with acceptable toxicity in $\mathrm{MBC}$, including patients pretreated with anthracyclines and taxanes. Eribulin $\left(1.4 \mathrm{mg} / \mathrm{m}^{2}\right)$ was initially administered on days 1,8 , and 15 of a 4-week cycle but caused significant neutropenia on day 15 [49], and was subsequently evaluated using dosing on days 1 and 8 of a 3-week cycle. Phase II trials were conducted in MBC patients who had received a median of four previous chemotherapy regimens; the first enrolled anthracycline and taxane-pretreated patients, and the second enrolled patients previously treated with anthracyclines, taxanes, and capecitabine (Table 3) [49, 50]. Eribulin produced objective responses in 11.5 and $9.3 \%$ of patients in the first and second trial, respectively, and clinical benefit (which includes stable disease $\geq 6$ months) in $17 \%$ of patients in both studies [49, 50]. Median OS was 9.0 months in the first trial and 10.4 months in the second trial.

On the basis of the phase II results, two open-label, randomized, phase III trials evaluated eribulin monotherapy [52]. The first trial (EMBRACE) compared eribulin versus the physician's choice of treatment in 762 patients with anthracycline and taxane-pretreated locally recurrent or MBC [51]. Patients were required to have received two to five previous 


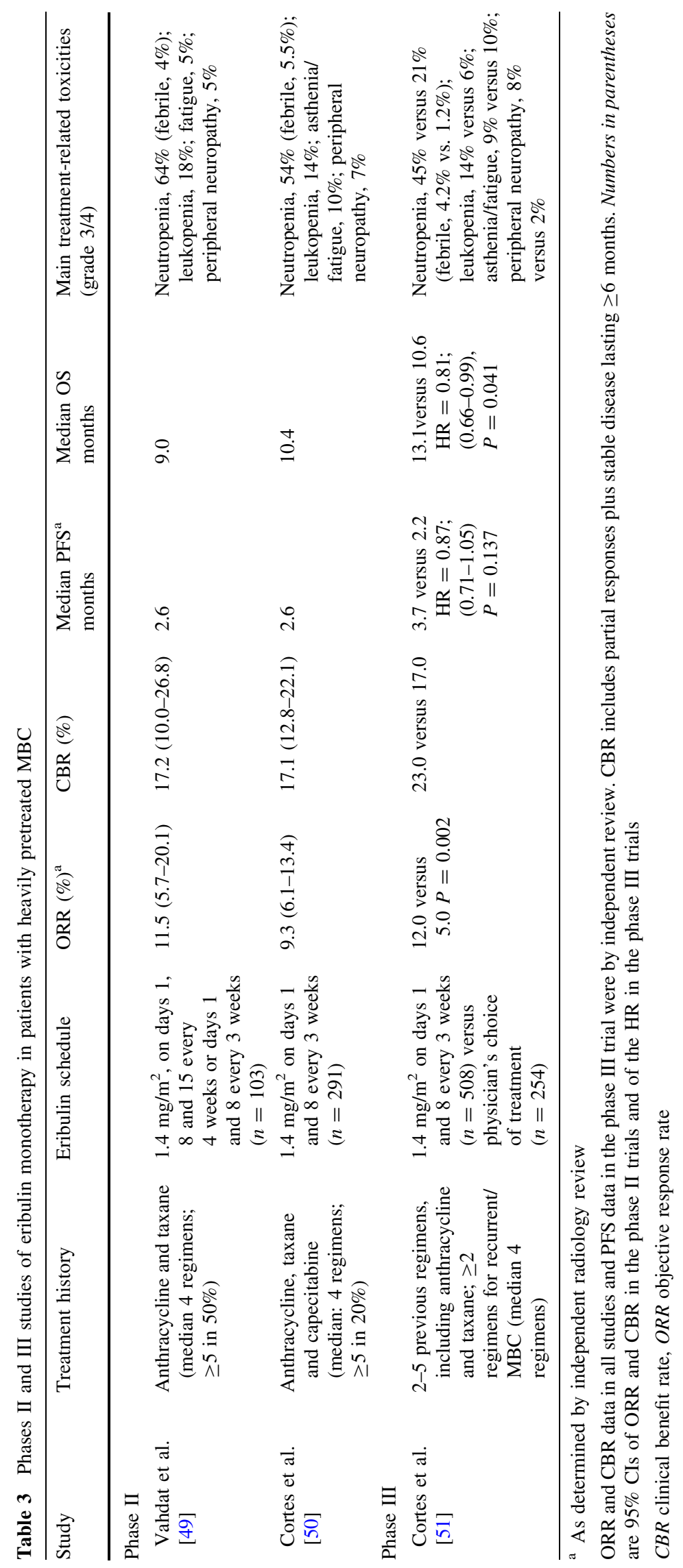


chemotherapy regimens, including at least two regimens for recurrent or $\mathrm{MBC} ; 73 \%$ had previously received capecitabine. The physician's choice included any monotherapy, and no patients received supportive care alone. In total, $96 \%$ received chemotherapy, most commonly vinorelbine, gemcitabine, or capecitabine. Eribulin significantly improved median OS compared with the physician's treatment choice (13.1 vs. 10.6 months; $P=0.041$; Table 3 ). On independent review, eribulin also produced a higher response rate (12 vs. $5 \%$; $P=0.002)$ and showed a trend for improving PFS (3.7 vs. 2.2 months; $P=0.137)$. Eribulin had a manageable tolerability profile, with grade $3 / 4$ neutropenia in $45 \%$ of patients. Notably, EMBRACE is the first phase III study to show a survival benefit for single-agent therapy in heavily pretreated MBC patients. The other phase III trial is comparing eribulin versus capecitabine in 1,102 locally advanced or MBC patients who had received up to three prior chemotherapy regimens including an anthracycline and a taxane, but no more than two regimens for advanced or MBC [52].

Ispinesib

The kinesin spindle protein plays an essential role in spindle formation during mitosis; its inhibition leads to mitotic arrest, formation of characteristic monoaster spindles, and ultimately apoptosis [53]. Ispinesib is a potent and selective small molecule inhibitor of the kinesin spindle protein. In preclinical evaluations, ispinesib had broad antiproliferative activity against a panel of breast cancer cell lines and induced tumor regression in breast cancer xenografts [54]. In these latter models, ispinesib enhanced the antitumor activity of trastuzumab, lapatinib, doxorubicin, and capecitabine. In a phase II trial, ispinesib produced a response rate of $9 \%$ in patients with locally advanced or MBC who had relapsed after prior treatment with an anthracycline and a taxane, and exhibited a relatively low neurotoxicity, gastrointestinal toxicity, and hair loss [55]. When administered on days 1, 8, and 15 of a 4-week cycle, the maximum tolerated dose (MTD) in patients with advanced solid tumors was $7 \mathrm{mg} / \mathrm{m}^{2}$ and neutropenia was the dose-limiting toxicity [56]. Stable disease was the best response in 9 of 30 patients. Several phase I trials have evaluated ispinesib in combination with docetaxel, carboplatin, or capecitabine in patients with advanced solid tumors, and identified a MTD [57-59]. According to ClinicalTrials.gov, there are no active trials ongoing with ispinesib in breast cancer.

\section{Vinflunine}

Vinflunine is a semi-synthetic fluorinated vinca alkaloid that suppresses microtubule dynamics and treadmilling, and blocks microtubule assembly, which leads to cell-cycle arrest, accumulation of cells in mitosis, and apoptosis [60]. Preclinical data suggest that vinflunine has potential for treatment of a wide range of solid tumors, including breast cancer with greater antitumor activity than vinorelbine [60]. However, vinflunine is sensitive to P-glycoproteinmediated resistance like other vinca alkaloids although it appears less likely to induce resistance than vinorelbine [60]. Vinflunine $320 \mathrm{mg} / \mathrm{m}^{2}$ every 3 weeks was active with predictable and manageable toxicity when administered to MBC patients after prior anthracycline and taxane therapy, producing response rates of 30 and $12.5 \%$ when used in second-line and third-line therapy, respectively [61, 62]. Median PFS was 3.7 and 2.6 months, respectively, and median OS was 14.3 and 11.4 months, respectively. The most common grade 3/4 adverse events in these phase II trials were neutropenia (65-70\%), fatigue (14-17\%), and constipation (7-12\%). In another phase II trial, vinflunine plus trastuzumab produced responses in $33 \%$, clinical benefit in $71 \%$, and PFS of 6.2 months in first-line therapy of MBC, but no advantages compared with taxane/trastuzumab or vinorelbine/trastuzumab in this setting [63]. Vinflunine is currently undergoing phase III evaluation in combination with capecitabine versus capecitabine alone in MBC previously treated with an anthracycline and a taxane, and as monotherapy versus the physician's choice of an alkylating agent in heavily pretreated MBC.

\section{Other agents}

Two other microtubule inhibitors are currently being evaluated in phase II trials for MBC. Tesetaxel (DJ-927) is an orally bioavailable docetaxel analog with greater antitumor activity than paclitaxel or docetaxel against a wide range of tumor cell lines and tumor xenografts [64]. Importantly, this agent remains active in tumor cells expressing P-glycoprotein. It is currently being evaluated as first-line therapy at a dose of $50 \mathrm{mg}$ every 3 weeks.

Indibulin (D-24851) is an orally active agent that destabilizes microtubules. Unlike the vinca alkaloids, indibulin can distinguish between highly modified $\beta$-tubulin found in mature neuronal microtubules and less-modified tubulin in non-neuronal microtubules, thereby offering the potential for reduced risk of neuropathy [65]. Indibulin has activity against a wide range of tumor cell lines, including cells resistant to taxanes, vinca alkaloids, and anthracyclines [66] and is under evaluation in a phase I/II trial in MBC.

\section{Individualizing MBC therapy beyond taxanes}

The most appropriate use of non-taxane microtubule-targeting agents in clinical practice remains to be defined. Clearly, use of these agents in taxane-naïve patients will 
require clinical evidence of equivalent efficacy compared with the standard-of-care taxanes, and their use following taxane failure will require continued evidence of clinical benefit. Patient/clinical characteristics, treatment history, and patient preference are important factors for non-taxane therapy in MBC. Key patient/clinical characteristics include tumor type (e.g., triple-negative breast cancer, HER2-positive disease), the presence of visceral disease, prognosis, and performance status. Ixabepilone appears to be a useful treatment option for patients with these difficult-to-treat attributes. Treatment history includes the use of taxanes and non-taxanes, number of previous regimens, previous single versus combination therapy, and availability of alternative options. Eribulin or ixabepilone plus capecitabine are effective options after previous taxane and anthracycline failure, and single-agent ixabepilone is an option once capecitabine has been used.

\section{Conclusions}

Taxanes are likely to remain a standard first-choice treatment for $\mathrm{MBC}$ in the near future. However, drug resistance often compromises the clinical benefits of taxanes, particularly in patients exposed to multiple lines of therapy. The use of other microtubule-targeting agents, such as ixabepilone or eribulin may bring clinical benefit to patients with taxane-resistant MBC who otherwise have very few therapeutic options. Ixabepilone has low susceptibility to most mechanisms conferring taxane resistance and has activity in patients across multiple lines of therapy in the advanced/metastatic disease setting. The recent approval of eribulin after second-line MBC treatment expands the treatment options available for patients with late-stage disease. In addition, several emerging novel microtubuletargeting agents appear to have therapeutic potential in MBC. Ixabepilone with or without capecitabine is a viable option for use in first-line or second-line therapy depending on whether taxanes had been used in the neoadjuvant or adjuvant settings, and eribulin is a promising option for use after second-line therapy. The development of these microtubule inhibitors helps to address the need for additional effective regimens for patients progressing after standard treatment with anthracycline- and taxane-containing regimens.

Acknowledgments The authors take full responsibility for the content of this publication and confirm that it reflects their viewpoint and medical expertise. The authors also wish to acknowledge StemScientific, funded by Bristol-Myers Squibb, for providing writing and editorial support. Neither Bristol-Myers Squibb nor StemScientific influenced the content of the manuscript, nor did the authors receive financial compensation for authoring the manuscript.
Conflict of interest The authors have the following disclosures: Dr. Cortes has received remuneration from Roche and Eisai, and has been a consultant for Roche and Novartis. Dr. Vidal has no relevant conflict of interest to disclose.

Open Access This article is distributed under the terms of the Creative Commons Attribution Noncommercial License which permits any noncommercial use, distribution, and reproduction in any medium, provided the original author(s) and source are credited.

\section{References}

1. Telli ML, Carlson RW (2009) First-line chemotherapy for metastatic breast cancer. Clin Breast Cancer 9(suppl 2):S66-S72

2. Surveillance epidemiology and end results. SEER stat fact sheets: breast. http://seer.cancer.gov/statfacts/html/breast.html\#survival. Accessed 4 Nov 2010

3. Cardoso F, Senkus-Konefka E, Fallowfield L, Costa A, Castiglione M (2010) Locally recurrent or metastatic breast cancer: ESMO clinical practice guidelines for diagnosis, treatment and follow-up. Ann Oncol 21(suppl 5):v15-v19

4. Yardley DA (2008) Activity of ixabepilone in patients with metastatic breast cancer with primary resistance to taxanes. Clin Breast Cancer 8(6):487-492

5. Moreno-Aspitia A, Perez EA (2009) Treatment options for breast cancer resistant to anthracyclines and taxane. Mayo Clin Proc 84(6):533-545

6. National comprehensive cancer network. NCCN clinical practice guidelines in oncology ${ }^{\mathrm{T}}$. Breast cancer. V.3.2010. http://www. nccn.org. Accessed 4 Nov 2010

7. Miller K, Wang M, Gralow J, Dickler M, Cobleigh M, Perez EA et al (2007) Paclitaxel plus bevacizumab versus paclitaxel alone for metastatic breast cancer. N Engl J Med 357(26):2666-2676

8. Miles DW, Chan A, Dirix LY, Cortes J, Pivot X, Tomczak P et al (2010) Phase III study of bevacizumab plus docetaxel compared with placebo plus docetaxel for the first-line treatment of human epidermal growth factor receptor 2-negative metastatic breast cancer. J Clin Oncol 28(20):3239-3247

9. Robert NJ, Dieras V, Glaspy J, Brufsky A, Bondarenko I, Lipatov O et al (2011) RIBBON-1: randomized, double-blind, placebocontrolled, phase III trial of chemotherapy with or without bevacizumab for first-line treatment of human epidermal growth factor receptor 2-negative, locally recurrent or metastatic breast cancer. J Clin Oncol 29(10):1252-1260

10. Broglio KR, Berry DA (2009) Detecting an overall survival benefit that is derived from progression-free survival. J Natl Cancer Inst 101(23):1642-1649

11. McGrogan BT, Gilmartin B, Carney DN, McCann A (2008) Taxanes, microtubules and chemoresistant breast cancer. Biochim Biophys Acta 1785(2):96-132

12. Fojo T, Menefee M (2007) Mechanisms of multidrug resistance: the potential role of microtubule-stabilizing agents. Ann Oncol 18(suppl 5):v3-v8

13. Chien AJ, Moasser MM (2008) Cellular mechanisms of resistance to anthracyclines and taxanes in cancer: intrinsic and acquired. Sem Oncol 35(suppl 2):S1-S14

14. Katsetos CD, Legido A, Perentes E, Mork SJ (2003) Class III $\beta$ tubulin isotype: a key cytoskeletal protein at the crossroads of developmental neurobiology and tumor neuropathology. J Child Neurol 18(12):851-866

15. Kamath K, Wilson L, Cabral F, Jordan MA (2005) $\beta$ III-tubulin induces paclitaxel resistance in association with reduced effects 
on microtubule dynamic instability. J Biol Chem 280(13): 12902-12907

16. Magnani M, Ortuso F, Soro S, Alcaro S, Tramontano A, Botta M (2006) The $\beta \mathrm{I} / \beta \mathrm{III}$-tubulin isoforms and their complexes with antimitotic agents. Docking and molecular dynamics studies. FEBS J 273(14):3301-3310

17. Paradiso A, Mangia A, Chiriatti A, Tommasi S, Zito A, Latorre A et al (2005) Biomarkers predictive for clinical efficacy of taxolbased chemotherapy in advanced breast cancer. Ann Oncol 16(suppl 4):iv14-iv19

18. Tommasi S, Mangia A, Lacalamita R, Bellizzi A, Fedele V, Chiriatti A et al (2007) Cytoskeleton and paclitaxel sensitivity in breast cancer: the role of $\beta$-tubulins. Int J Cancer 120(10):20782085

19. Gerth K, Bedorf N, Hofle G, Irschik H, Reichenbach H (1996) Epothilons A and B: antifungal and cytotoxic compounds from Sorangium cellulosum (Myxobacteria). Production, physicochemical and biological properties. J Antibiot (Tokyo) 49(6): 560-563

20. Rivera E, Lee J, Davies A (2008) Clinical development of ixabepilone and other epothilones in patients with advanced solid tumors. Oncologist 13(12):1207-1223

21. Vahdat L (2008) Ixabepilone: a novel antineoplastic agent with low susceptibility to multiple tumor resistance mechanisms. Oncologist 13(3):214-221

22. Jordan M, Miller H, Ni L, Castenada S, Inigo I, Kan D et al. (2006) The Pat-21 breast cancer model derived from a patient with primary Taxol resistance recapitulates the phenotype of its origin, has altered beta-tubulin expression, and is sensitive to ixabepilone. Proc Am Assoc Cancer Res 47:abstract LB-280

23. Lee FY, Smykla R, Johnston K, Menard K, McGlinchey K, Peterson RW et al (2009) Preclinical efficacy spectrum and pharmacokinetics of ixabepilone. Cancer Chemother Pharmacol 63(2):201-212

24. Lee FY, Borzilleri R, Fairchild CR, Kim SH, Long BH, Reventos-Suarez C et al (2001) BMS-247550: a novel epothilone ana$\log$ with a mode of action similar to paclitaxel but possessing superior antitumor efficacy. Clin Cancer Res 7(5):1429-1437

25. Lee FY, Camuso A, Castaneda S, Flefleh C, Ingio I, Kan D et al. (2006) Preclinical efficacy evaluation of ixabepilone (BMS247550) in combination with cetuximab or capecitabine in human colon and lung carcinoma xenografts. J Clin Oncol 24(suppl):abstract 12017

26. Lee FYF, Covello KL, Castaneda S, Hawken DR, Kan D, Lewin A et al (2008) Synergistic antitumor activity of ixabepilone (BMS-247550) plus bevacizumab in multiple in vivo tumor models. Clin Cancer Res 14(24):8123-8131

27. Perez EA, Lerzo G, Pivot X, Thomas E, Vahdat L, Bosserman L et al (2007) Efficacy and safety of ixabepilone (BMS-247550) in a phase II study of patients with advanced breast cancer resistant to an anthracycline, a taxane and capecitabine. J Clin Oncol 25(23):3407-3414

28. Thomas E, Tabernero J, Fornier M, Conte P, Fumoleau P, Lluch A et al (2007) Phase II clinical trial of ixabepilone (BMS247550), an epothilone B analog, in patients with taxane-resistant metastatic breast cancer. J Clin Oncol 25(23):3399-3406

29. Roche H, Yelle L, Cognetti F, Mauriac L, Bunnell C, Sparano J et al (2007) Phase II clinical trial of ixabepilone (BMS-247550), an epothilone B analog, as first-line therapy in patients with metastatic breast cancer previously treated with anthracycline chemotherapy. J Clin Oncol 25(23):3415-3420

30. Low JA, Wedam SB, Lee JJ, Berman AW, Brufsky A, Yang SX et al (2005) Phase II clinical trial of ixabepilone (BMS-247550), an epothilone B analog, in metastatic and locally advanced breast cancer. J Clin Oncol 23(12):2726-2734
31. Denduluri N, Low JA, Lee JJ, Berman AW, Walshe JM, Vatas U et al (2007) Phase II trial of ixabepilone, an epothilone B analog, in patients with metastatic breast cancer previously untreated with taxanes. J Clin Oncol 25(23):3421-3427

32. Thomas E, Gomez HL, Li RK, Chung HC, Fein LE, Chan VF et al (2007) Ixabepilone plus capecitabine for metastatic breast cancer progressing after anthracycline and taxane treatment. J Clin Oncol 25(33):5210-5217

33. Hortobagyi GN, Gomez HL, Li RK, Chung HC, Fein LE, Chan $\mathrm{VF}$ et al (2010) Analysis of overall survival from a phase III study of ixabepilone plus capecitabine versus capecitabine in patients with $\mathrm{MBC}$ resistant to anthracyclines and taxanes. Breast Cancer Res Treat 122(2):409-418

34. Sparano JA, Vrdoljak E, Rixe O, Xu B, Manikhas A, Medina C et al (2010) Randomized phase III trial of ixabepilone plus capecitabine in patients with metastatic breast cancer previously treated with an anthracycline and a taxane. J Clin Oncol 28(20):3256-3263

35. Conte P, Roche H, Perez E, Sparano J, Xu B, Jassem J et al. (2009) Ixabepilone plus capecitabine improves overall survival in symptomatic patients with metastatic breast cancer previously treated with anthracycline and taxane in 2 large phase III studies. Cancer Res 69(suppl):abstract 6114

36. Perez EA, Patel T, Moreno-Aspitia A (2010) Efficacy of ixabepilone in ER/PR/HER2-negative (triple-negative) breast cancer. Breast Cancer Res Treat 121(2):261-271

37. Roche H, Conte P, Perez EA, Sparano JA, Xu B, Jassem J et al (2011) Ixabepilone plus capecitabine in metastatic breast cancer patients with reduced performance status previously treated with anthracyclines and taxanes: a pooled analysis by performance status of efficacy and safety data from 2 phase III studies. Breast Cancer Res Treat 125(3):755-765

38. Rugo HS, Roche H, Thomas E, Blackwell K, Chung HC, Lerzo G et al. (2009) Ixabepilone plus capecitabine vs capecitabine in patients with triple-negative tumors: a pooled analysis of patients from two large phase III clinical studies. Cancer Res 69(suppl):abstract 3057

39. Yardley DA (2010) Visceral disease in patients with metastatic breast cancer: efficacy and safety of treatment with ixabepilone and other chemotherapeutic agents. Clin Breast Cancer 10(1):64-71

40. Moulder S, Li H, Gradishar WJ, Gradishar WJ, Perez EA, Sparano JA et al (2010) A phase II trial of trastuzumab plus weekly ixabepilone and carboplatin in patients with HER2positive metastatic breast cancer: an eastern cooperative oncology group trial. Breast Cancer Res Treat 119(3):663-667

41. Chuang E, Wiener N, Christos P, Kessler R, Cobham M, Donovan D et al (2010) Phase I trial of ixabepilone plus pegylated liposomal doxorubicin in patients with adenocarcinoma of breast or ovary. Ann Oncol 21(10):2075-2080

42. Roche H, Zambetti M, Dalenc F, Govi S, Gladieff L, Mudenda B et al. (2008) Phase Ib study of ixabepilone (I) in combination with epirubicin (E) in women with metastatic breast cancer. J Clin Oncol 26(suppl):abstract 1058

43. Rugo HS, Campone M, Amadori D, Wardley AM, Aldrighetti D, Conte PF et al. (2010) Randomized phase II study of weekly versus every 3 week ixabepilone plus bevacizumab (ixa/bev) versus paclitaxel plus bev (pac/bev) as first-line therapy for metastatic breast cancer (MBC): final results. J Clin Oncol 28(suppl):abstract 1040

44. Cheng KL, Bradley T, Budman DR (2008) Novel microtubuletargeting agents- the epothilones. Biologics 2(4):789-811

45. Conlin AK, D'Andrea G, Hudis CA, Robson ME, Drullinsky P, Theodoulou $\mathrm{M}$ et al. (2008) Phase II trial of patupilone in patients with breast cancer brain metastases (BCBM) progressing or 
recurring after whole brain radiation therapy (WBXRT). J Clin Oncol 26(suppl):abstract 1086

46. Morrow PK, Divers S, Provencher L, Luoh SW, Petrella TM, Giurescu $M$ et al (2010) Phase II study evaluating the efficacy and safety of sagopilone (ZK-EPO) in patients with metastatic breast cancer that has progressed following chemotherapy. Breast Cancer Res Treat 123(3):837-842

47. Cigler T, Vahdat LT (2010) Eribulin mesylate for the treatment of breast cancer. Expert Opin Pharmacother 11(9):1587-1593

48. Kuznetsov G, Towle MJ, Cheng H, Kawamura T, TenDyke K, Liu D et al (2004) Induction of morphological and biochemical apoptosis following prolonged mitotic blockage by halchondrin B macrocyclic ketone analog E7389. Cancer Res 64(16):5760-5766

49. Vahdat LT, Pruitt B, Fabian CJ, Rivera RR, Smith DA, Tan-Chiu E et al (2009) Phase II study of eribulin mesylate, a halichondrin $\mathrm{B}$ analog, in patients with metastatic breast cancer previously treated with an anthracycline and a taxane. J Clin Oncol 27(18):2954-2961

50. Cortes J, Vahdat L, Blum JL, Twelves C, Campone M, Roche H et al (2010) Phase II study of the halichondrin B analog eribulin mesylate in patients with locally advanced or metastatic breast cancer previously treated with an anthracycline, a taxane, and capecitabine. J Clin Oncol 28(25):3922-3928

51. Cortes J, O'Shaughnessy J, Loesch D, Blum JL, Vahdat L, Petrakova $\mathrm{K}$ et al (2011) Eribulin monotherapy versus treatment of physician's choice in patients with metastatic breast cancer (EMBRACE): a phase 3 open-label randomised study. Lancet 377(9769):914-923

52. Twelves C, Cortes J, Vahdat LT, Wanders J, Akerele C, Kaufman PA (2010) Phase III trials of eribulin mesylate (E7389) in extensively pretreated patients with locally recurrent or metastatic breast cancer. Clin Breast Cancer 10(2):160-163

53. Zhang Y, Xu W (2008) Progress on kinesin spindle inhibitors as anti-cancer agents. Anticancer Agents Med Chem 8(6):698-704

54. Purcell JW, Davis J, Reddy M, Martin S, Samayoa K, Vo H et al (2010) Activity of the kinesin spindle protein inhibitor ispinesib (SB-715992) in models of breast cancer. Clin Cancer Res 16(2):566-576

55. Miller,K, Ng C, Ang P, Brufsky AM, Lee SC, Dees EC et al. (2005) Phase II, open label study of SB-715992 (Ispinesib) in subjects with advanced or metastatic breast cancer. Breast Cancer Res Treat 94(suppl):abstract 1089

56. Burris HA III, Jones SF, Williams DD, Kathman SJ, Hodge JP, Pandite L et al (2011) A phase I study of ispinesib, a kinesin spindle inhibitor, administered weekly for three consecutive weeks of a 28-day cycle in patients with solid tumors. Invest New Drugs 29(3):467-472

57. Blagden SP, Molife LR, Seebaran A, Payne M, Reid AH, Protheroe AS et al (2008) A phase I trial of ispinesib, a kinesin spindle inhibitor, with docetaxel in patients with advanced tumors. Br J Cancer 98(5):894-899

58. Jones SF, Plummer ER, Burris HA, Razak AR, Meluch AA, Bowen CJ et al. (2006) Phase I study of ispinesib in combination with carboplatin in patients with advanced solid tumors. J Clin Oncol 24(suppl):abstract 2027

59. Rodon J, Till E, Patnaik A, Takimoto C, Beeram M, Williams D et al. (2006) Phase I study of ispinesib (SB-715992), a kinesin spindle protein inhibitor, in combination with capecitabine in patients with advanced solid tumors. Eur J Cancer Supp 4(12):abstract 640

60. Bennouna J, Delord J-P, Campone M, Nguyen L (2008) Vinflunine: a new microtubule inhibitor agent. Clin Cancer Res 14(6):1625-1632

61. Campone M, Cortes-Funes H, Vorobiof D, Martin M, Slabber CF, Ciruelos E et al (2006) Vinflunine: a new active drug for second-line treatment of advanced breast cancer, Results of a phase II and pharmacokinetic study inpatients progressing after first-line anthracycline/taxane-based chemotherapy. Br J Cancer 95(9):1161-1166

62. Fumoleau P, Cortes-Funes $\mathrm{H}$, Taleb AB, Chan S, Campone M, Pouget JC et al (2009) Phase 2 study of single-agent IV vinflunine as third-line treatment of metastatic breast cancer after failure of anthracycline-/taxane-based chemotherapy. Am J Clin Oncol 32(4):375-380

63. Yardley DA, McCleod M, Schreiber F, Yardley DA, McCleod M, Schreiber F et al (2010) A phase II trial of vinflunine as monotherapy or in combination with trastuzumab as first-line treatment of metastatic breast cancer. Cancer Invest 28(9):925-931

64. Shionoya M, Jimbo T, Kitagawa M, Soga T, Tohgo A (2003) DJ927, a novel oral taxane, overcomes P-glycoprotein-mediated multidrug resistance in vitro and in vivo. Cancer Sci 94(5):459-466

65. Wiencke A, Bacher G (2009) Indibulin, a novel microtubule inhibitor, discriminates between mature neuronal and nonneuronal tubulin. Cancer Res 69(1):171-177

66. Bacher G, Nickel B, Emig P, Vanhoefer U, Seeber S, Shandra A et al (2001) D-24851, a novel synthetic microtubule inhibitor, exerts curative antitumoral activity in vivo, shows efficacy toward multidrug-resistant tumor cells, and lacks neurotoxicity. Cancer Res 61(1):392-399 